\title{
Replace routine preoperative testing with individualized risk assessment and indicated testing
}

\author{
Evidence indicates no benefit for certain testing that has, to this point, \\ been considered standard practice for low-risk patients undergoing \\ noncardiac surgery, say these authors
}

\author{
Emily B. Wang, MD, MPH, and Kimberly A. Kho, MD, MPH
}

\section{IN THIS} ARTICLE

Tests to consider

this page

Serum chemistries page 41

Diagnostic studies page 43

\section{CASE Patient questions need} for preoperative tests

A healthy 42-year-old woman (G2P2) with abnormal uterine bleeding and a 2-cm endometrial polyp is scheduled for hysteroscopic polypectomy. After your preoperative clinic visit, the patient receives her paperwork containing information about preoperative lab work and diagnostic studies. You are asked to come into the room because she has further questions. When you arrive, the patient holds the papers out and asks, "Is all this blood work and a chest x-ray necessary? I thought I was healthy and this was a fairly simple surgery. Is there more I should be worried about?"

How would you respond?

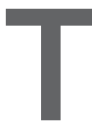
he goal of preoperative testing is to determine which patients may be at an increased risk for experiencing an adverse perioperative event, taking into

Dr. Wang is MIGS Fellow and Assistant Instructor, Department of Obstetrics and Gynecology, University of Texas Southwestern Medical Center, Dallas, Texas.

Dr. Kho is Director of the Fellowship in Minimally Invasive Gynecologic Surgery, University of Texas Southwestern Medical Center, Dallas, Texas.

Dr. Kho reports serving on the scientific advisory board for Myovant Sciences. Dr. Wang reports no financial relationships relevant to this article.

doi: 10.12788 /obgm.0054 account both the inherent risks of the surgical procedure and the health of the individual patient. In the literature, the general consensus is that physicians rely too heavily on unnecessary laboratory and diagnostic testing during their preoperative assessment. ${ }^{1}$ More than $50 \%$ of patients who underwent preoperative evaluation had at least 1 unindicated test. ${ }^{2}$ These tests may result in a high frequency of abnormal findings, with less than $3 \%$ of abnormalities having clinical value or leading to a change in management. ${ }^{3}$

With health care costs accounting for almost $20 \%$ of the gross domestic product in the United States (totaling about $\$ 3.5$ billion in 2017), performing unindicated preoperative testing contributes to the economic burden on health care systems, with an estimated cost of $\$ 3$ to $\$ 18$ million annually. ${ }^{4,5}$ In addition, unindicated tests can increase patient anxiety and necessitate follow-up testing, possibly exposing physicians to increased liability if abnormal results are not adequately investigated. ${ }^{6}$

It is time to rethink our use of routine preoperative testing.

\section{Which tests to consider-or} not: Evidence-based guidance

Professional societies, including the American Board of Internal Medicine's Choosing 
TABLE 1 Physical status classification system of the American Society of Anesthesiologists ${ }^{8}$

\begin{tabular}{|c|c|c|}
\hline Class & Definition & Examples including, but not limited to \\
\hline ASA I & Normal healthy patient & Healthy, nonsmoker, no or minimal alcohol use \\
\hline ASA II & Mild systemic disease & $\begin{array}{l}\text { Mild disease only without substantive functional limitations: current smoker, social alcohol } \\
\left.\text { drinker, pregnancy, obesity (BMI, } 30-40 \mathrm{~kg} / \mathrm{m}^{2}\right) \text {, well-controlled DM/HTN, mild lung } \\
\text { disease }\end{array}$ \\
\hline ASA III & $\begin{array}{l}\text { Severe systemic } \\
\text { disease }\end{array}$ & $\begin{array}{l}\text { One or more moderate-to-severe diseases with substantive functional limitations: alcohol } \\
\left.\text { dependence or abuse, poorly controlled DM/HTN, COPD, morbid obesity (BMI }>40 \mathrm{~kg} / \mathrm{m}^{2}\right) \text {, } \\
\text { active hepatitis, implanted pacemaker, moderate reduction of ejection fraction, ESRD } \\
\text { undergoing regular scheduled dialysis, history ( }>3 \text { months) of MI, CVA, TIA, or CAD/stents }\end{array}$ \\
\hline ASA IV & $\begin{array}{l}\text { Severe systemic } \\
\text { disease that is a } \\
\text { constant threat to life }\end{array}$ & $\begin{array}{l}\text { Recent ( }<3 \text { months) MI, CVA, TIA, or CAD/stents, ongoing cardiac ischemia or severe } \\
\text { valve dysfunctional severe reduction of ejection fraction, sepsis, DIC, ESRD not } \\
\text { undergoing regularly scheduled dialysis }\end{array}$ \\
\hline
\end{tabular}

Abbreviations: ASA, American Society of Anesthesiologists; BMI, body mass index; CAD, coronary artery disease; COPD, chronic obstructive pulmonary disease; CVA, cerebrovascular accident; DIC, disseminated intravascular coagulation; DM, diabetes mellitus; ESRD, end-stage renal disease; HTN, hypertension; MI, myocardial infarction; TIA, transient ischemic attack.

Wisely campaign, promote a move away from routine testing to avoid unnecessary visits and studies. In addition, the American Society of Anesthesiologists (ASA) has published recommendations to guide preoperative testing. ${ }^{7}$ To stratify patients' surgical risk according to their pre-existing health conditions, the ASA created a physical status classification system (TABLE 1). ${ }^{8}$

In addition to individual patient characteristics, some guidelines similarly stratify surgical procedures into minor, intermediate, and major risk. The modified Johns Hopkins surgical criteria allocates surgical risk based on expected blood loss, insensible loss, and the inherent risk of a procedure separate from anesthesia (TABLE 2, page 42). ${ }^{9}$ Despite these guidelines, physicians responsible for preoperative evaluations continue to order laboratory and diagnostic tests that are not indicated, often over concerns of case delays or cancellations..$^{10,11}$

The following evidence-based recommendations provide guidance to gynecologists performing surgery for benign indications to determine which preoperative studies should be performed.

\section{Serum chemistries}

Basic metabolic panel (BMP). In both contemporary studies and earlier prospective studies, a preoperative BMP has a low likelihood of changing the surgical procedure or the patient's management, especially in patients who are classified as ASA I and are undergoing minor- and intermediate-risk procedures. ${ }^{12,13}$ Therefore, we recommend a BMP for patients in class ASA II or higher who are undergoing intermediate-risk or major surgery. ${ }^{14}$

Thyroid function. A basic tenet of preoperative evaluation is that asymptomatic patients should not be diagnosed according to lab values prior to surgical intervention. Therefore, we do not recommend routine preoperative thyroid function testing in patients without a history of thyroid disease. ${ }^{10}$ For patients with known thyroid disease, a thyroid stimulating hormone (TSH) level should be evaluated prior to major surgery, or with any changes in medication dose or symptoms, within the past year. ${ }^{15}$

Liver function tests (LFTs). Routine screening of asymptomatic individuals without risk factors for liver disease is not recommended because there is a significantly lower incidence of abnormal lab values for LFTs than for other lab tests. ${ }^{16}$ We recommend LFTs only in symptomatic patients or patients diagnosed with severe liver disease undergoing intermediate-risk or major procedures. ${ }^{14}$

Hemoglobin A1c (HbA1c). Poorly controlled diabetes is a risk factor for poor wound healing, hospital readmission, prolonged hospitalization, and adverse events following surgery. ${ }^{17}$ We recommend that HbAlc

\begin{tabular}{l} 
FAST \\
TRACK \\
\hline In addition to \\
individual patient \\
characteristics, \\
some guidelines \\
similarly stratify \\
surgical procedures \\
into minor, \\
intermediate, \\
and major risk
\end{tabular}

FAST

In addition to individual patient characteristics, some guidelines similarly stratify surgical procedures into minor, and major risk 
TABLE 2 Estimating surgical risk $^{9}$

\begin{tabular}{|c|c|c|c|c|c|}
\hline $\begin{array}{l}\text { Surgical } \\
\text { risk }\end{array}$ & $\begin{array}{l}\text { JHRCS } \\
\text { category }\end{array}$ & Description & $\begin{array}{l}\text { Expected } \\
\text { blood loss }\end{array}$ & Exclusions & Examples ${ }^{a}$ \\
\hline Minimal & 1 & $\begin{array}{l}\text { Minimal risk to patient } \\
\text { independent of ASA } \\
\text { Often done in office } \\
\text { setting, operating } \\
\text { room primarily used for } \\
\text { anesthesia/monitoring }\end{array}$ & Little or none & $\begin{array}{l}\text { Open exposure of internal } \\
\text { organs } \\
\text { Entry into abdomen } \\
\text { Placement of prosthetic } \\
\text { devices } \\
\text { Planned postoperative ICU } \\
\text { care }\end{array}$ & $\begin{array}{l}\text { Hysteroscopy } \\
\text { Wide local excision } \\
\text { Loop electrosurgical } \\
\text { excisional procedure } \\
\text { Dilation and curettage }\end{array}$ \\
\hline Intermediate & 2 & $\begin{array}{l}\text { Minimal to moderate } \\
\text { invasive } \\
\text { Mild risk to patient } \\
\text { independent of } \\
\text { anesthesia }\end{array}$ & $<500 \mathrm{~mL}$ & $\begin{array}{l}\text { Open exposure of internal } \\
\text { organs } \\
\text { Placement of prosthetic } \\
\text { devices }\end{array}$ & $\begin{array}{l}\text { Diagnostic } \\
\text { laparoscopy } \\
\text { Myomectomy } \\
\text { Laparoscopic lysis of } \\
\text { adhesions, ovarian } \\
\text { cystectomy, resection } \\
\text { of endometriosis } \\
\text { Laparoscopic/vaginal } \\
\text { hysterectomy }\end{array}$ \\
\hline Major & 3 & $\begin{array}{l}\text { Moderately to } \\
\text { significantly invasive } \\
\text { Moderate risk to } \\
\text { patient independent of } \\
\text { anesthesia }\end{array}$ & $500-1,000 \mathrm{~mL}$ & $\begin{array}{l}\text { Major vasculature repair } \\
\text { Open thoracic or intracranial } \\
\text { procedures } \\
\text { Planned postoperative ICU } \\
\text { care }\end{array}$ & $\begin{array}{l}\text { Abdominal } \\
\text { hysterectomy } \\
\text { Myomectomy } \\
\text { (multiple) } \\
\text { Resection of Stage IV } \\
\text { endometriosis } \\
\text { Emergent procedures }^{\mathrm{b}}\end{array}$ \\
\hline Major + & 4 & $\begin{array}{l}\text { Highly invasive } \\
\text { Major risk to patient } \\
\text { independent of } \\
\text { anesthesia }\end{array}$ & $>1,500 \mathrm{~mL}$ & & $\begin{array}{l}\text { Major gastrointestinal } \\
\text { tract reconstruction }\end{array}$ \\
\hline $\begin{array}{l}\text { Abbreviations: As } \\
\text { a'Modified JHRCS } \\
\text { 'E Emergent proce }\end{array}$ & d examples & $\begin{array}{l}\text { Anesthesiologists; ICU, intens } \\
\text { necologic procedures. }\end{array}$ & are unit; JHRCS, & Hopkins risk classification system. & \\
\hline
\end{tabular}

levels be drawn only for patients with known diabetes undergoing intermediate-risk or major surgery who do not have an available lab value within the past 3 months. ${ }^{14}$

\section{Hematologic studies}

Complete blood count (CBC). Many patients undergoing gynecologic procedures may have unreported or undiagnosed anemia secondary to abnormal uterine bleeding, which also may encompass heavy menstrual bleeding. With an abnormal CBC likely to affect preoperative management, assessment of preoperative hemoglobin levels is critical so that hemoglobin levels can be appropriately corrected before surgery. We therefore recommend obtaining a $\mathrm{CBC}$ for patients in class ASA II or higher who are undergoing intermediate-risk or major surgery. ${ }^{10,14}$

Coagulation studies. Preoperative coagulation studies are unlikely to uncover previously undiagnosed inherited coagulopathies, which are generally uncommon in the general population, and they do not predict operative bleeding when ordered unnecessarily. ${ }^{18,19}$ Therefore, we recommend preoperative coagulation studies only in patients 1) currently on anticoagulation therapy undergoing intermediate-risk or major surgery or 2) in class ASA III or higher with bleeding disorders or cirrhosis undergoing intermediate-risk or major surgery. ${ }^{14}$ 
Type and screen (T\&S). Complicated algorithms have been proposed to determine when a preoperative $T \& S$ is necessary, but these may be impractical for busy gynecologists. ${ }^{20}$ We recommend a T\&S within 72 hours, or on the day, of surgery for all patients undergoing major surgery, including hysterectomy, or with an anticipated blood loss of more than $500 \mathrm{~mL}$; routine crossmatching of blood is not recommended. ${ }^{10,14}$

\section{Urologic studies}

Urine pregnancy test. Although the probability of a positive pregnancy test is likely very low, its occurrence frequently leads to the cancellation of surgery. We therefore recommend a preoperative urine pregnancy test, particularly in reproductive-aged patients with unknown pregnancy status or unreliable contraceptive habits. ${ }^{14}$ Preoperative urine pregnancy testing, even in patients who report sexual inactivity, ideally should be individualized and based on risk of fetal harm during or subsequent to surgery. Surgeries involving the uterus, or those involving possible teratogens like radiation, also should be considered when making recommendations for testing.

Urinalysis and urine culture. In asymptomatic patients undergoing general gynecologic procedures, a routine preoperative urinalysis and urine culture are of little value. ${ }^{18}$ However, among patients undergoing a urogynecologic surgical procedure, the risk of a postoperative urinary tract infection is higher than among patients undergoing a nonurogynecologic procedure. ${ }^{21,22}$ Therefore, we typically do not recommend routine preoperative urinalysis or urine culture, but a preoperative urine culture may be beneficial in patients undergoing urogynecologic surgery. ${ }^{14}$

\section{Diagnostic studies}

Electrocardiography (ECG). The absolute difference in cardiovascular death is less than $1 \%$ among patients with and without ECG abnormalities undergoing a noncardiac procedure with minimal to moderate risk; therefore, routine ECG for low-risk patients should not be performed. ${ }^{23}$ Instead, ECG should be performed in patients with known coronary artery disease or structural heart disease and in patients aged 65 years and older, since age older than 65 years is an independent predictor of significant ECG abnormalities. ${ }^{24,25} \mathrm{We}$ therefore recommend that the following individuals have an ECG within the last 12 months: patients aged 65 years and older, patients in class ASA II or higher with cardiovascular disease, and patients in class ASA III or higher undergoing general anesthesia. If there is a change in cardiovascular health since the most recent ECG-even if it was performed within 12 months-a repeat ECG is warranted. ${ }^{10,14}$

Chest x-ray. Despite a high rate of abnormalities seen on routine and indicated chest $x$-rays, there is no significant difference in perioperative pulmonary complications among patients with a normal or abnormal chest $\mathrm{x}$-ray. ${ }^{16}$ Rather than changing surgical management, these abnormal results are more likely to lead to the cancellation or postponement of a surgical procedure. ${ }^{7}$ We therefore recommend against routine preoperative chest $\mathrm{x}$-ray. ${ }^{14}$

\section{The bottom line}

Preoperative testing serves as an additional component of surgical planning. The fact is, however, that abnormal test results are common and frequently do not correlate with surgical outcomes. ${ }^{26}$ Instead, they can lead to unnecessary surgical procedure cancellations or postponements, undue anxiety in patients, increased liability among physicians, and rising health care costs. ${ }^{5-7}$

Rather than overly relying on routine laboratory or diagnostic studies, the history and physical examination should continue to be the cornerstone for surgeons responsible for assessing surgical risk. With individualized risk assessment, specific, indicated testing rather than routine nonspecific testing can be obtained. ${ }^{10,14}$ In short, low-risk patients undergoing noncardiac surgery are unlikely to benefit from preoperative ECG, chest x-ray, or routine laboratory testing without clinical indication.

For Table 3: Recommendations for preoperative testing, read the online version of this article at mdedge.com/obgyn. $\overline{\text { FAST }}$ TRACK

We recommend a preoperative urine pregnancy test, particularly in reproductiveaged patients with unknown pregnancy status or unreliable contraceptive habits

CONTINUED ON PAGE 44 


\section{References}

1. Kachalia A, Berg A, Fagerlin A, et al. Overuse of testing in preoperative evaluation and syncope: a survey of hospitalists. Ann Intern Med. 2015;162:100-108.

2. Onuoha OC, Hatch M, Miano TA, et al. The incidence of un-indicated preoperative testing in a tertiary academic ambulatory center: a retrospective cohort study. Perioper Med. 2015; 4:14.

3. Kaplan EB, Sheiner LB, Boeckmann AJ, et al. The usefulness of preoperative laboratory screening. JAMA. 1985;253:3576-3581.

4. Centers for Disease Control and Prevention National Center for Health Statistics. Table 42: Gross domestic product, national health expenditures, per capita amounts, percent distribution, and average annual percent change: United States, selected years 1960-2017. https://www.cdc.gov/nchs/ data/hus/2018/042.pdf. Accessed July 2020.

5. Benarroch-Gampel J, Sheffield KM, Duncan CB, et al. Preoperative laboratory testing in patients undergoing elective, low-risk ambulatory surgery. Ann Surg. 2012;256:518-528.

6. O'Neill F, Carter E, Pink N, et al. Routine preoperative tests for elective surgery: summary of updated NICE guidance. $B M J$. 2016;354: i3292.

7. Committee on Standards and Practice Parameters; Apfelbaum JL, Connis RT, Nickinovich DG, et al. Practice advisory for preanesthesia evaluation: an updated report by the American Society of Anesthesiologists Task Force on Preanesthesia Evaluation. Anesthesiology. 2012;116:522-538.

8. American Society of Anesthesiologists. ASA physical status classification system. https://www.asahq.org/standardsand-guidelines/asa-physical-status-classification-system. Accessed July 2020.

9. Pasternak LR, Johns A. Ambulatory gynaecological surgery: risk and assessment. Best Pract Res Clin Obstet Gynaecol. 2005;19:663-679.

10. Shields J, Lupo A, Walsh T, et al. Preoperative evaluation for gynecologic surgery: a guide to judicious, evidence-based testing. Curr Opin Obstet Gynecol. 2018;30:252-259.

11. Sigmund AE, Stevens ER, Blitz JD, et al. Use of preoperative testing and physicians' response to professional society guidance. JAMA Intern Med. 2015;175:1352-1359.

12. St Clair CM, Shah M, Diver EJ, et al. Adherence to evidence-based guidelines for preoperative testing in women undergoing gynecologic surgery. Obstet Gynecol. 2010;116:694-700.

13. De Sousa Soares D, Brandao RR, Mourao MR, et al. Relevance of routine testing in low-risk patients undergoing minor and medium surgical procedures. Braz J Anesthesiol. 2013;63:197-201
14. Shields J, Kho KA. Preoperative evaluation for minimally invasive gynecologic surgery: what is the best evidence and recommendations for clinical practice. J Minim Invasive Gynecol. 2019;26:312-320.

15. Palace MR. Perioperative management of thyroid dysfunction. Health Serv Insights. 2017;10:1178632916689677.

16. Smetana GW, Macpherson DS. The case against routine preoperative laboratory testing. Med Clin North Am. 2003;87:7-40.

17. Jehan F, Khan M, Sakran JV, et al. Perioperative glycemic control and postoperative complications in patients undergoing emergency general surgery: what is the role of plasma hemoglobin Alc? J Trauma Acute Care Surg. 2018;84:112-117.

18. Feely MA, Collins CS, Daniels PR, et al. Preoperative testing before noncardiac surgery: guidelines and recommendations. Am Fam Physician. 2013;87:414-418.

19. Rusk MH. Avoiding unnecessary preoperative testing. Med Clin North Am. 2016;100:1003-1008.

20. Dexter F, Ledolter J, Davis E, et al. Systematic criteria for type and screen based on procedure's probability of erythrocyte transfusion. Anesthesiology. 2012;116:768-778.

21. Gehrich AP, Lustik MB, Mehr AA, et al. Risk of postoperative urinary tract infections following midurethral sling operations in women undergoing hysterectomy. Int Urogynecol J. 2016;27:483-490

22. American College of Obstetricians and Gynecologists. ACOG practice bulletin No. 195 summary: prevention of infection after gynecologic procedures. Obstet Gynecol. 2018;131:11771179 .

23. Noordzij PG, Boersma E, Bax JJ, et al. Prognostic value of routine preoperative electrocardiography in patients undergoing noncardiac surgery. Am J Cardiol, 2006;97: 1103-1106.

24. Fleisher LA, Fleischmann KE, Auerbach AD, et al. 2014 ACC/ AHA guideline on perioperative cardiovascular examination and management of patients undergoing noncardiac surgery: executive summary: a report of the American College of Cardiology/American Heart Association Task Force on Practice Guidelines. Circulation. 2014;130:2215-2245.

25. Correll DJ, Hepner DL, Chang C, et al. Preoperative electrocardiograms: patient factors predictive of abnormalities. Anesthesiology. 2009;110:1217-1122.

26. Fritsch G, Flamm M, Hepner DL, et al Abnormal preoperative tests, pathologic findings of medical history, and their predictive value for perioperative complications. Acta Anaesthesiol Scand. 2012;56:339-350. 
TABLE 3 Recommendations for preoperative testing

\begin{tabular}{|c|c|c|}
\hline \multicolumn{2}{|c|}{ Laboratory test or study } & Recommendation \\
\hline \multirow[t]{5}{*}{ Serum } & Basic metabolic panel & ASA class $\geq I l$ undergoing intermediate-risk or major surgery \\
\hline & Thyroid function & $\begin{array}{l}\text { Not recommended for asymptomatic patients without a history } \\
\text { of thyroid disease }\end{array}$ \\
\hline & & $\begin{array}{l}\text { TSH for patients with known thyroid disease undergoing major surgery } \\
\text { without a TSH within the past } 12 \text { months or any recent changes } \\
\text { in medication dose or symptoms }\end{array}$ \\
\hline & Liver function tests & $\begin{array}{l}\text { Symptomatic patients or patients with severe liver disease undergoing } \\
\text { intermediate-risk or major surgery }\end{array}$ \\
\hline & Hemoglobin A1c & $\begin{array}{l}\text { Patients with known diabetes undergoing intermediate-risk or major surgery } \\
\text { without an } \mathrm{HbA} 1 \mathrm{c} \text { within the past } 3 \text { months }\end{array}$ \\
\hline \multirow[t]{5}{*}{ Hematology } & Complete blood count & ASA class $\geq I l$ undergoing intermediate-risk or major surgery \\
\hline & Coagulation studies & $\begin{array}{l}\text { Patients on anticoagulation therapy undergoing an intermediate-risk } \\
\text { or major surgery }\end{array}$ \\
\hline & & $\begin{array}{l}\text { ASA class } \geq \text { III with bleeding disorders or cirrhosis undergoing } \\
\text { intermediate-risk or major surgery }\end{array}$ \\
\hline & Type and screen & $\begin{array}{l}\text { All patients undergoing major surgery or with an expected blood loss } \\
>500 \mathrm{~mL}\end{array}$ \\
\hline & & Routine crossmatching is not recommended \\
\hline \multirow[t]{3}{*}{ Urine } & Urine pregnancy test & $\begin{array}{l}\text { All reproductive-aged patients, specifically those with unknown pregnancy } \\
\text { status or unreliable contraceptive habits }\end{array}$ \\
\hline & Urinalysis and urine culture & Not recommended routinely \\
\hline & & Urine culture can be considered in patients undergoing urogynecologic surgery \\
\hline Vaginal & Bacterial vaginosis screening & Consider in patients undergoing total hysterectomy \\
\hline \multirow[t]{6}{*}{ Diagnostic } & Electrocardiography & Recent ECG within the last 12 months in: \\
\hline & & - Patients aged $\geq 65$ years undergoing general anesthesia \\
\hline & & - ASA class $\geq$ Il with cardiovascular disease undergoing general anesthesia \\
\hline & & - ASA class $\geq 11$ l undergoing general anesthesia \\
\hline & & $\begin{array}{l}\text { Repeat ECG, even if last ECG was performed within } 12 \text { months, } \\
\text { for patients who have a change in cardiovascular health }\end{array}$ \\
\hline & Chest x-ray & Not recommended routinely \\
\hline
\end{tabular}

